\title{
ESTOQUES DE CARBONO ORGÂNICO E DE NITROGÊNIO NO SOLO EM SISTEMA DE INTEGRAÇÃO LAVOURA- PECUÁRIA EM PLANTIO DIRETO, SUBMETIDO A INTENSIDADES DE PASTEJO(1)
}

\author{
Edicarlos Damacena de Souza ${ }^{(2)}$, Sergio Ely Valadão Gigante de \\ Andrade Costa ${ }^{(3)}$, Ibanor Anghinoni ${ }^{(4)}$, Paulo César de Faccio \\ Carvalho $^{(5)}$, Marcelo Andrigueti ${ }^{(6)}$ \& Eduardo Cao ${ }^{(6)}$
}

\begin{abstract}
RESUMO
Sistemas de integração lavoura-pecuária têm um alto potencial de uso no sul do país, especialmente em áreas de soja sob plantio direto, com espécies de cobertura no inverno. A condução de sistemas de integração com diferentes intensidades de manejo da pastagem resultará, ao longo do tempo, em estoques de C orgânico (CO) e de $\mathrm{N}$ diferenciados, decorrentes do aporte diferenciado de resíduos. Este trabalho foi realizado para avaliar a evolução dos estoques de $\mathrm{CO}$ e de $\mathrm{N}$ total (NT) e em frações físicas da matéria orgânica em solo submetido a diferentes intensidades de pastejo, em plantio direto. $O$ experimento foi iniciado em 2001, em um Latossolo Vermelho distrófico, após a colheita da soja. Os tratamentos constaram de alturas de manejo da pastagem (aveia-preta + azevém): 10, 20 e $40 \mathrm{~cm}$, com bovinos jovens, e sem pastejo, seguido do cultivo de soja, em delineamento de blocos ao acaso. Amostras de solo foram retiradas no início do experimento (maio 2001), após três anos (maio de 2004) e após seis anos (maio de 2007), para a avaliação dos teores e dos estoques de CO e de NT. Intensidades de pastejo moderadas (20 e $40 \mathrm{~cm}$ de altura do pasto) promoveram aumento nos
\end{abstract}

\footnotetext{
(1) Parte da pesquisa de Tese de Doutorado do primeiro autor apresentada ao Programa de Pós-Graduação em Ciência do Solo da Universidade Federal do Rio Grande do Sul - UFRGS. Trabalho realizado com recursos da Agrisus e CNPq. Recebido para publicação em setembro de 2008 e aprovado em agosto de 2009.

(2) Pós-Doutorando do Programa de Pós-Graduação em Agronomia, Universidade Federal de Goiás - UFG. Caixa Postal 03 , CEP 75804-020 Jataí (GO). E-mail: edicarlos@pg.cnpq.br

(3) Mestre em Ciência do Solo - Universidade Federal do Rio Grande do Sul - UFRGS. E-mail: sergioelycosta@hotmail.com

(4) Professor do Departamento de Solos, UFRGS. Bolsista do CNPq. E-mail: ibanghi@ufrgs.br

(5) Professor de Departamento de Plantas Forrageiras e Agrometeorologia, UFRGS. Bolsista do CNPq. E-mail: paulocfc@ufrgs.br

${ }^{(6)}$ Graduando em Agronomia - UFRGS. E-mails: 00135966@ufrg.br; duda_cao@yahoo.com.br
} 
estoques de CO total, CO particulado, NT e N na matéria orgânica particulada no solo, semelhante ao plantio direto sem pastejo. Na alta intensidade de pastejo $(10 \mathrm{~cm})$, houve redução no estoque desses elementos, com degradação da qualidade da matéria orgânica.

Termos de indexação: aveia-preta + azevém, soja, índice de manejo de carbono.

\title{
SUMMARY: SOIL ORGANIC CARBON AND NITROGEN STOCKS IN AN UNTILLED CROP-LIVESTOCK INTEGRATION SYSTEMUNDER DIFFERENT GRAZING INTENSITIES
}

\begin{abstract}
The potential for adopting crop-livestock systems in southern Brazil is high, especially in untilled soybean areas with cover crops in the winter season. The long-term use of this system at different grazing intensities will result in different carbon and nitrogen stocks in the soil due to the different plant and animal residues. This research was conducted to evaluate alterations in total carbon and nitrogen pools and in organic matter fractions in a soil under different grazing intensities under no-tillage. The experiment on a Rhodic Hapludult (Oxisol) was initiated in 2001, after soybean harvest. The treatments were different cattle grazing (black oat + ryegrass) pressures (10,20 and $40 \mathrm{~cm}$ sward height) and an ungrazed treatment in the winter and soybean in the summer, in a randomized block design. Soil samples were taken at the beginning of the experiment (May, 2001), after three years (May, 2004) and after six years (May, 2007) to evaluate the content and stocks of organic carbon and nitrogen. Moderate grazing intensities (20 and $40 \mathrm{~cm}$ plant height) resulted in an increase of total carbon and nitrogen and in the organic matter particulate fraction, similarly to the ungrazed area. However, at the most intensive grazing pressure $(10 \mathrm{~cm}$ plant height) there were losses in the stocks of these elements and reduction in soil organic matter quality.
\end{abstract}

Index terms: black oat + ryegrass, soybean, carbon management index.

\section{INTRODUÇÃO}

O C e o N são os principais componentes da matéria orgânica do solo e os seus estoques irão variar em função das taxas de adição, por resíduos vegetais e, ou, animais, e de perda, dentre elas, as decorrentes da erosão e da oxidação pelos microrganismos do solo. Em solos sem ação antrópica, o teor e o estoque desses elementos são determinados basicamente pela temperatura, pela umidade e pelo tipo de solo (Bayer \& Mielniczuk, 1997).

Em sistemas agrícolas, os estoques de C orgânico (CO) e de $\mathrm{N}$ total (NT) no solo são também influenciados pelo manejo adotado. Em solos com intenso revolvimento, além das perdas por erosão, ocorre aumento da atividade microbiana pela maior exposição dos resíduos aos microrganismos e suas enzimas. Assim, um Argissolo de ambiente subtropical, submetido ao plantio convencional, necessitou de uma adição anual de $19,7 \mathrm{Mg} \mathrm{ha}^{-1}$ de resíduos vegetais ( $45 \%$ de $\mathrm{C}$ ) para manter os estoques originais de matéria orgânica do solo, e, quando submetido ao plantio direto, essa adição foi de somente 9,3 $\mathrm{Mg} \mathrm{ha}^{-1}$ (Lovato et al., 2004).
O aumento no estoque de matéria orgânica do solo é proveniente do sequestro de $\mathrm{C}$ atmosférico, via fotossíntese, sendo, do ponto de vista ambiental, muito importante na mitigação da emissão de gases do efeito estufa (Lal, 2002). O entendimento da dinâmica da matéria orgânica no solo somente ocorrerá em estudos que levem em consideração o tempo, pois a evolução dos seus teores no solo e as respectivas interações decorrentes das práticas de manejo adotadas tendem a ser lentas.

Em sistemas de integração lavoura-pecuária, em plantio direto, ocorre aporte diferenciado de resíduos vegetais em relação aos sistemas puros de produção de grãos, tanto na superfície quanto no perfil do solo pelas raízes (Salton et al., 2002). Em alta intensidade de pastejo, ocorre maior crescimento radicular (Souza et al., 2008) tanto da pastagem quanto da cultura de grãos integrante do sistema e, com isso, o aporte de matéria orgânica em profundidade será influenciado. Dessa forma, a condução desses sistemas por longo tempo em plantio direto, com diferentes intensidades de manejo da pastagem, resultará em adições diferenciadas de resíduos vegetais ao solo em adição aos resíduos de origem animal. Com essa adição 
diferenciada de resíduos ao solo, devem-se ter diferentes estoques de $\mathrm{CO}$ e de NT, principalmente na fração particulada, como verificado no sistema plantio direto com plantas de cobertura e produção de grãos (Conceição et al., 2005; Boeni, 2007). Com isso, espera-se que, nas áreas com maior intensidade de pastejo, ocorra maior saída de $\mathrm{C}$ e de $\mathrm{N}$ do sistema, devido às perdas por respiração microbiana e pelo pastejo animal e, como consequência, haja menor estoque desses elementos no solo.

O C e o N na fração particulada, por ser a fração mais sensível às alterações no solo, serão os primeiros a indicar as alterações no balanço desses nutrientes no solo (Conceição et al., 2005), sendo as perdas mais pronunciadas nas áreas com maiores intensidades de pastejo. O objetivo deste trabalho foi avaliar a evolução dos estoques de $\mathrm{CO}$ e de NT e em frações físicas da matéria orgânica em sistema de integração lavourapecuária submetido a diferentes intensidades de pastejo em plantio direto.

\section{MATERIAL E MÉTODOS}

$\mathrm{O}$ experimento faz parte de um projeto integrado entre os Departamentos de Solos e de Plantas Forrageiras e Agrometeorologia da Universidade Federal do Rio Grande do Sul. O trabalho vem sendo realizado desde maio de 2001, em área localizada na Fazenda do Espinilho, pertencente à Cabanha Cerro Coroado, cuja sede está localizada no município de São Miguel das Missões, na região ecoclimática do Planalto Médio - RS.

O solo foi classificado como Latossolo Vermelho distroférrico (Embrapa, 2006) profundo bem drenado e textura muito argilosa $\left(0,54 \mathrm{~kg} \mathrm{~kg}^{-1}\right.$ de argila, $0,27 \mathrm{~kg} \mathrm{~kg}^{-1}$ de silte e $0,19 \mathrm{~kg} \mathrm{~kg}^{-1}$ de areia). Antes do início do experimento, a área vinha sendo cultivada, em plantio direto, por 10 anos, com aveia-preta (Avena strigosa Schreb) no inverno e soja (Glycine max) no verão.

Antes da implantação do primeiro ciclo da cultura da soja, em novembro de 2001, foi feita uma aplicação superficial de calcário em toda a área, na dosagem de 4,5 Mg ha-1 (PRNT de $62 \%$ ), recomendada para elevar o pH do solo até 5,5 para o sistema de plantio direto consolidado (CQFSRS/SC, 2004). No mês de maio de 2001, após a colheita da soja, o experimento foi instalado com estabelecimento da pastagem de aveiapreta + azevém (Lolium multiflorum Lam.). A área total do experimento é de aproximadamente 22 ha, e foi dividida em parcelas experimentais, com tamanhos variando de 1,0 a 2,5 ha aproximadamente, em função dos tratamentos aplicados. Os tratamentos constaram de diferentes alturas de manejo da pastagem: 10, 20, $40 \mathrm{~cm}$ e sem pastejo, distribuídas num delineamento experimental de blocos ao acaso, com três repetições, sendo a altura da pastagem acompanhada a cada 14 dias, pelo método Sward Stick (Bircham, 1981). As alturas de manejo da pastagem foram obtidas pela variação da carga animal de acordo com as alturas verificadas: retirando-se animais das parcelas experimentais quando a altura real era menor que a pretendida, e vice-versa. Geralmente, o número de animais utilizados em cada parcela foi quatro, dois e um animal por hectare para as alturas de manejo da pastagem de 10, 20 e $40 \mathrm{~cm}$, respectivamente. Desde a implantação dos tratamentos ao longo dos anos, em torno de 45 dias após a semeadura da pastagem, foi realizada uma adubação nitrogenada de cobertura, com dose variando de 45 a $90 \mathrm{~kg} \mathrm{ha}^{-1}$ de $\mathrm{N}$ na forma de ureia. A quantidade de $\mathrm{N}$ aplicada foi a mesma para todos os tratamentos em cada ano, não sendo dessa forma uma fonte de variação.

O método de pastejo adotado foi o contínuo, e, geralmente, os animais entravam na área quando a pastagem atingia um acúmulo médio em torno de $1.500 \mathrm{~kg} \mathrm{ha}^{-1}$ de MS. De forma geral, os animais iniciavam o ciclo de pastejo na primeira quinzena de julho, que se estendia até a primeira quinzena de novembro. Foram utilizados bovinos jovens, com idade em torno de 12 meses. Após a retirada dos animais, a pastagem era dessecada para a realização da semeadura da soja, que ocorria em meados de novembro, no sistema plantio direto, sendo os tratos culturais os recomendados para a cultura. O cultivar utilizado foi a Iguaçu, num espaçamento entre linhas de $45 \mathrm{~cm}$. A adubação de base constou da aplicação de $300 \mathrm{~kg} \mathrm{ha}^{-1}$ das fórmulas 0-20-30, 5-20-20, 0-2030, 0-20-30, 0-20-30 e 0-20-30 nos anos-safra 2001/ 02, 2002/03, 2003/04, 2004/05, 2005/06 e 2006/07, respectivamente, e as sementes foram tratadas com inoculante específico. As colheitas foram realizadas nos meses de abril e maio de cada ano.

Para a coleta das amostras de solo, foram abertas trincheiras de $30 \times 20 \times 25 \mathrm{~cm}$ e, posteriormente, com uma pá de corte, retirou-se um bloco de solo. Do bloco coletado, foram retiradas, com auxílio de uma espátula, amostras das camadas de 0 a 2,$5 ; 2,5$ a $5 ; 5$ a 7,$5 ; 7,5$ a $10 ; 10$ a 15 ; e 15 a $20 \mathrm{~cm}$ no início do experimento (maio de 2001), três anos após (maio de 2004) e seis anos após (maio de 2007). Esse procedimento foi repetido em oito pontos por parcela, para formar uma amostra composta representativa do tratamento. Após a coleta, as amostras foram acondicionadas em sacos plásticos e transportadas até o Laboratório de Fertilidade do Solo do Departamento de Solos da UFRGS, secas ao ar e passadas em peneiras de $2 \mathrm{~mm}$ para as análises.

Foi realizado o fracionamento físico da matéria orgânica segundo Cambardella \& Elliot (1992): 20 g de solo foram colocados em frascos do tipo "snap-cap" de $180 \mathrm{~mL}$ e adicionados $80 \mathrm{~mL}$ de solução de hexametafosfato de sódio $\left(5 \mathrm{~g} \mathrm{~L}^{-1}\right)$. As amostras foram agitadas por $15 \mathrm{~h}$ em agitador horizontal. Posteriormente, a suspensão foi passada em peneira de $53 \mu \mathrm{m}$ com auxílio de jatos de água. O material retido na 
peneira foi seco em estufa a $50^{\circ} \mathrm{C}$ até massa constante, moído em gral de porcelana e analisado quanto ao seu teor de CO, denominado CO particulado (COP). Os teores de $\mathrm{C}$ total e particulado foram analisados por combustão seca em equipamento Shimadzu TOCV CSH. O N total do solo (NT) e da fração particulada da matéria orgânica do solo foram determinados pelo método de Kjeldahl, segundo Tedesco et al. (1995).

Os estoques de COT, NT, COP e N na fração particulada no solo foram calculados em massas equivalentes de solo. Este método leva em conta a massa do solo dos tratamentos em relação ao solo com a maior massa, o que é tido como referência (Ellert \& Bettany, 1995). Dessa forma, o cálculo dos estoques foram baseados nas densidades de solo de 1,21 e $1,36 \mathrm{~kg} \mathrm{dm}^{-3}$ para as camadas de 0 a 2,5 e 2,5 a 5,0 cm, respectivamente; para as demais camadas foi utilizada a densidade de 1,35 $\mathrm{kg} \mathrm{dm}^{-3}$. Para o cálculo do estoque total de $\mathrm{C}$ e $\mathrm{N}$ e das frações foi realizada a soma dos estoques em cada camada amostrada.

O cálculo do Índice de Manejo do Carbono (IMC) e de seus componentes foi efetuado nas amostras coletadas em maio de 2007, a partir da proposta original de Blair et al. (1995) com as adaptações de Diekow (2005), que considera o COP representante da fração lábil do COT e o CO associado aos minerais (que é representado pela diferença entre o COT e o COP) como não lábil.

Os resultados das análises de solo foram submetidos à análise de variância e, quando significativos, empregou-se o teste de Tukey $(\mathrm{p}<0,05)$, utilizando o seguinte modelo estatístico para a análise da variância, com restrição ao fator tempo (épocas de amostragem):

$$
\begin{gathered}
\text { Yijk }=\mu+B i+A j+\operatorname{erroa}(i, j)+C k+\operatorname{errob}(i, k)+ \\
\text { ACjk }+\operatorname{erroc}(i, j, k)
\end{gathered}
$$

sendo $\mathrm{B}=$ blocos $(\mathrm{i}=1,2,3) ; \mathrm{A}=$ intensidades de pastejo $(\mathrm{j}=1,2,3,4) ; \mathrm{C}=$ épocas de amostragem $(\mathrm{k}=1,2,3)$.

\section{RESULTADOS E DISCUSSÃO}

Os estoques de $\mathrm{C}$ e de $\mathrm{N}$ total do solo tiveram um aumento a partir da instalação do experimento no ano de 2001 (Figura 1a,b). Os teores iniciais (51 $\mathrm{Mg} \mathrm{ha}^{-1}$ de $\mathrm{C} \mathrm{e} 4.400 \mathrm{~kg} \mathrm{ha}^{-1}$ de N) são altos, devido à proteção da matéria orgânica nesse tipo de solo ser elevada (Boeni, 2007) e pelo fato de que a área do experimento vinha sendo cultivada em plantio direto por 10 anos. $\mathrm{O}$ aumento de $3,47 \mathrm{Mg} \mathrm{ha}^{-1}$ no estoque de $\mathrm{C}$ em três anos, o que representa um incremento médio anual de $1,16 \mathrm{Mg} \mathrm{ha}^{-1}$ (Figura 1a), é considerado alto (Corazza et al., 1999). Para o N, foi verificado um aumento no estoque de $345 \mathrm{~kg} \mathrm{ha}^{-1}$, representando um aporte anual médio de $115 \mathrm{~kg} \mathrm{ha}^{-1}$. Aumentos nos estoques de $\mathrm{C}$ e $\mathrm{N}$ em todas as intensidades de pastejo nos anos iniciais de realização do trabalho eram esperados, uma vez que houve aplicação de $\mathrm{N}$ na pastagem de inverno e inserção do animal nas áreas pastejadas. A adição de resíduos orgânicos provoca alterações no solo, como maior agregação e, consequentemente, maior proteção da matéria orgânica, além de uma reorganização da estrutura do solo, promovendo menores perdas de C e de N (Salton, 2005; Boeni, 2007).

Aportes de $\mathrm{C}$ na ordem de $0,81 \mathrm{Mg}$ ha $\mathrm{ano}^{-1}$, verificados por Sá (2001) na camada de 0-20 cm de um Latossolo argiloso sob plantio direto, com plantas de trigo e plantas de cobertura no inverno e de soja e milho no verão, fazem com que esse solo seja classificado como de grande potencial de sequestrar C atmosférico. Na comparação com esse sistema, o de integração lavoura-pecuária, objeto deste estudo, pode ter potencial ainda maior, no sentido de auxiliar no aumento da matéria orgânica do solo com consequente redução dos gases causadores do efeito estufa na atmosfera.
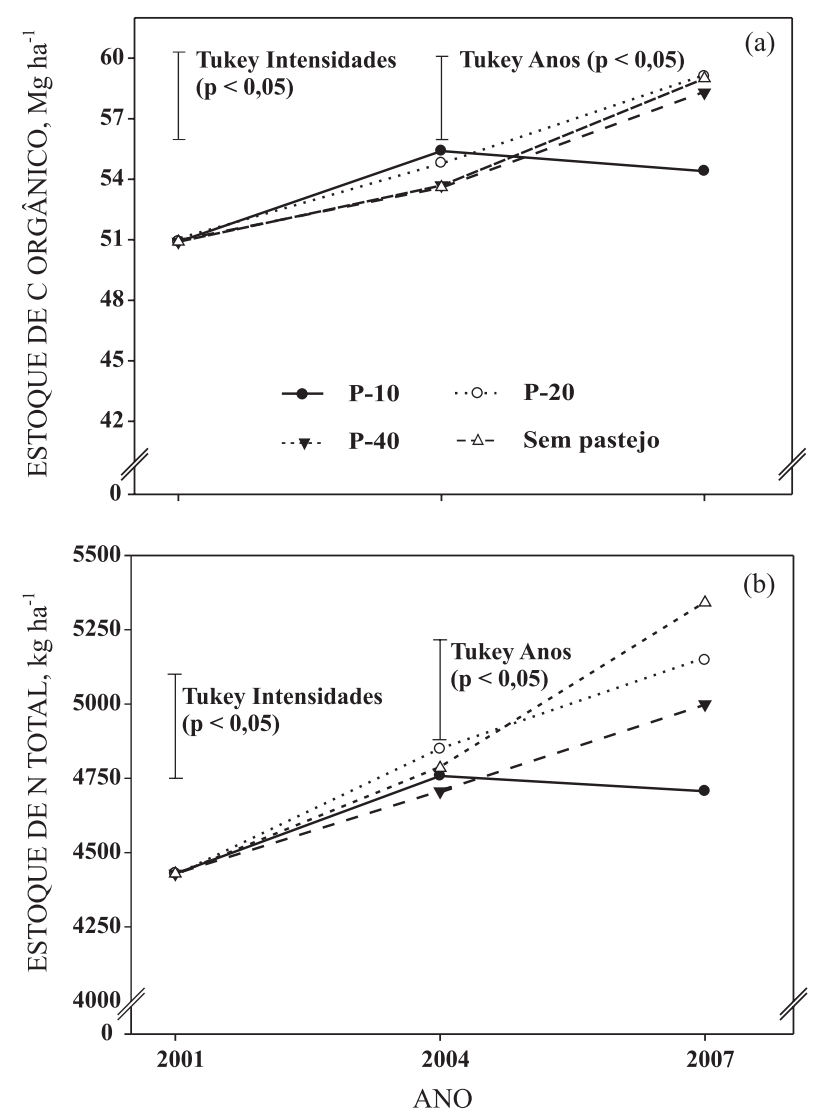

Figura 1. Estoques de carbono orgânico total (a) e nitrogênio total (b) na camada de 0 a $20 \mathrm{~cm}$ em um Latossolo Vermelho distroférrico sob sistema de integração lavoura-pecuária em plantio direto, submetido a intensidades de pastejo. $\mathrm{P}-10, \mathrm{P}-20$ e $\mathrm{P}-40$ representam alturas de pastejo de 10, 20 e $40 \mathrm{~cm}$, respectivamente. 
Influência das intensidades de pastejo nos estoques totais de $\mathrm{C}$ e $\mathrm{N}$, no entanto, somente foram verificadas no sexto ano (Figura 1a,b), em função das adições dos resíduos resultantes do manejo da pastagem em diferentes intensidades. Houve aumento linear desses nutrientes do primeiro para o sexto ano em todos os tratamentos, com exceção do pastejo de $10 \mathrm{~cm}$, que, tanto para o $\mathrm{C}$ como para o $\mathrm{N}$ total, tendeu a um aumento após três anos e, depois, a um decréscimo, sem porém, apresentar diferenças $(p>0,05)$ em relação aos teores iniciais.

As taxas anuais de adição de $\mathrm{C}$ e $\mathrm{N}$, tendo como referência o início do experimento, demonstram que as adições desses nutrientes ao solo variaram em função da intensidade de pastejo e do tempo. Verificase que, inicialmente, as maiores intensidades de pastejo tenderam a maiores acúmulos de C; entretanto, com o tempo de realização do sistema, isso se inverteu (Quadro 1), demonstrando que ocorreram perdas de C especialmente no tratamento de maior intensidade de pastejo em relação ao verificado no terceiro ano. Comportamento semelhante também foi verificado para o N após seis anos (Quadro 2), sem, no entanto, haver diferenças entre as intensidades de pastejo no terceiro ano (Quadro 2 e Figura 1b). As perdas de C, do terceiro para o sexto ano, na maior intensidade de pastejo, chegaram a $1,0 \mathrm{Mg} \mathrm{ha}^{-1}$, com taxa de perda de $0,33 \mathrm{Mg}$ ha $\mathrm{ano}^{-1}$, enquanto as de $\mathrm{N}$ foram de $52 \mathrm{~kg} \mathrm{ha}{ }^{-1}$, com taxa de perda de $17,4 \mathrm{~kg}$ ha ano-1 (Quadro 1).

Espera-se que as áreas com intensidades leves a moderadas de pastejo, assim como a área sem pastejo, tenham aumentos menos pronunciados, em relação aos observados agora, nos estoques de $\mathrm{C}$ e $\mathrm{N}$ total com o tempo, uma vez que há um limite de acúmulo de matéria orgânica para os solos em geral (Diekow et al., 2005). Entretanto, as perdas nos estoques desses elementos na maior intensidade de pastejo possivelmente continuam ocorrendo, visto que a adição de resíduos pela parte aérea nesse tratamento e a exportação pelos produtos comerciais gerados (carne e grãos) e as perdas via respiração microbiana (Souza, 2008) são muito superiores às verificadas nas demais intensidades de manejo da pastagem.

Assim como ocorreu para o C e o N total (Figura 1a,b), o $\mathrm{C}$ e o $\mathrm{N}$ na fração particulada da matéria orgânica obteve uma tendência de acúmulo nos diferentes manejos da pastagem, após três anos de realização do experimento (Figura 2a,b). No entanto, aos seis anos de realização, a exemplo do que aconteceu com os respectivos estoques totais desses elementos, essa tendência deixou de existir ou mesmo tomou sentido decrescente nos seus estoques, como verificado na fração particulada na maior intensidade de pastejo (Figura 1a,b). A fração particulada é a mais lábil da matéria orgânica e é tida como um eficiente indicador do manejo adotado no solo (Conceição et al., 2005). Essa fração demonstra, neste estudo, que na área com maior intensidade de pastejo $(10 \mathrm{~cm})$ está havendo a degradação da matéria orgânica a partir do terceiro ano, em função de sua tendência de diminuição.

Trabalhos realizados na mesma área deste estudo (Cassol, 2003; Souza et al., 2008, Lopes, 2008) têm demonstrado que as intensidades de pastejo influenciam grandemente a quantidade total de resíduos orgânicos adicionados ao solo, influenciando assim a entrada de C e N no sistema, uma vez que há relação direta entre a altura do pasto e a massa de forragem da parte aérea. Da mesma forma, a intensidade de pastejo tem influenciado a massa de raízes, que tem sido, porém, inversamente proporcional à altura do pasto (Souza et al., 2008; Souza, 2008).

Quadro 1. Estimativa da taxa de adição anual de carbono orgânico e nitrogênio total em diferentes intensidades de pastejo em relação ao início do experimento em um Latossolo Vermelho distroférrico sob sistema de integração lavoura-pecuária em plantio direto

\begin{tabular}{|c|c|c|c|c|c|}
\hline \multirow{2}{*}{ Intensidades de pastejo } & \multicolumn{2}{|c|}{ Incremento } & \multirow[b]{2}{*}{ Tempo } & \multicolumn{2}{|c|}{ Taxa de adição anual } \\
\hline & C & $\mathbf{N}$ & & C & $\mathbf{N}$ \\
\hline & $\mathrm{Mg} \mathrm{ha}^{-1}$ & $\mathrm{~kg} \mathrm{ha}^{-1}$ & $\operatorname{ano}(\mathrm{s})$ & $\mathrm{Mg} \mathrm{ha}^{-1}$ & $\mathrm{~kg} \mathrm{ha}^{-1}$ \\
\hline $\mathrm{P}-10^{(1)}$ & 4,5 & 329 & $(3)$ & 1,5 & 110 \\
\hline P-20 & 3,9 & 419 & (3) & 1,3 & 140 \\
\hline $\mathrm{P}-40$ & 2,8 & 277 & (3) & 0,9 & 92 \\
\hline Sem pastejo & 2,7 & 356 & (3) & 0,9 & 118 \\
\hline P-10 & 3,5 & 277 & -2001 a 2007 & 0,6 & 46 \\
\hline $\mathrm{P}-20$ & 8,2 & 718 & (6) & 1,4 & 120 \\
\hline P- 40 & 7,4 & 570 & (6) & 1,2 & 95 \\
\hline Sem pastejo & 8,1 & 912 & $(6)$ & 1,3 & 152 \\
\hline
\end{tabular}

(1) P-10, P-20 e P-40 representam alturas de pastejo de 10, 20 e $40 \mathrm{~cm}$, respectivamente. 
Quadro 2. Índice de estoque de carbono (IEC), labilidade (L), índice de labilidade (IL) e índice de manejo de carbono (IMC), na camada de 0 a $20 \mathrm{~cm}$, em um Latossolo Vermelho em sistema de integração lavoura-pecuária em plantio direto, submetido a intensidades de pastejo

\begin{tabular}{ccccr}
\hline $\begin{array}{c}\text { Intensidade } \\
\text { de pastejo }\end{array}$ & IEC & L & IL & IMC \\
\hline P-10 & $0,884 \mathrm{~b}$ & $0,102 \mathrm{~b}$ & $0,733 \mathrm{~b}$ & $65 \mathrm{~b}$ \\
P-20 & $0,986 \mathrm{a}$ & $0,131 \mathrm{a}$ & $1,072 \mathrm{a}$ & $107 \mathrm{a}$ \\
P-40 & $0,955 \mathrm{a}$ & $0,146 \mathrm{a}$ & $1,045 \mathrm{a}$ & $100 \mathrm{a}$ \\
Sem pastejo $^{(1)}$ & - & $0,140 \mathrm{a}$ & - & $100 \mathrm{a}$ \\
\hline
\end{tabular}

${ }^{(1)}$ Referência, com IMC 100. Valores seguidos de mesma letra na coluna não diferem pelo teste de Tukey $(\mathrm{p}<0,05)$. P-10, P20 e P-40 representam alturas de pastejo de 10,20 e $40 \mathrm{~cm}$, respectivamente.
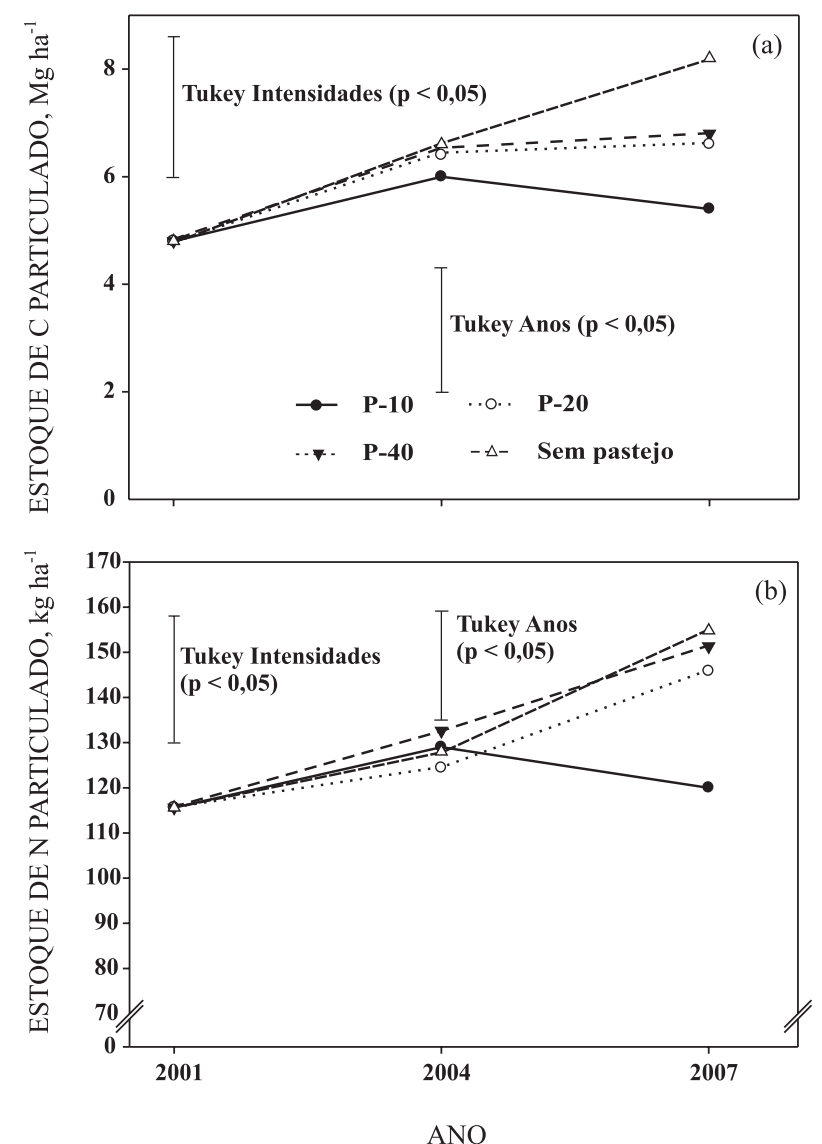

Figura 2. Estoques de carbono orgânico particulado (a) e nitrogênio na matéria orgânica particulada (MOP) (b) na camada de 0 a $20 \mathrm{~cm}$ em um Latossolo Vermelho distroférrico sob sistema de integração lavoura-pecuária em plantio direto, submetido a intensidades de pastejo. P-10, P-20 e $\mathrm{P}-40$ representam alturas de pastejo de 10,20 e $40 \mathrm{~cm}$, respectivamente.
A intensidade de pastejo, além da quantidade de resíduos depositados, afeta também o modo como os animais distribuem os dejetos na área. Em intensidades moderadas de pastejo ( $20 \mathrm{~cm}$ de altura do pasto), não há falta e nem excesso de forragem a ponto de haver seleção por parte dos animais no pastejo, assim como o tempo em que os animais passam pastejando é menor (Baggio, 2007). Após pastejar, o animal irá ruminar e, com isso, a distribuição dos dejetos pode ser mais concentrada em determinados locais. Já em situações de baixa oferta ou baixa qualidade de forragem, o animal caminha mais para adquirir todo alimento que necessita (Baggio, 2007) e, assim, o tempo de ruminação é menor e ele acaba distribuindo os dejetos em vários pontos da área. Isso irá alterar a distribuição do material orgânico lábil nessas áreas, fazendo com que a atividade microbiana seja diferenciada. Já na área em que o pastejo é excluído, os resíduos vegetais são melhor distribuídos e menos decomponíveis pelos microrganismos, em relação aos das áreas pastejadas.

Utilizando os dados de Lopes (2008), pode-se efetuar uma estimativa de quanto $\mathrm{C}$ é ingerido por animal, baseando-se no seu consumo diário para as intensidades de 10 e $40 \mathrm{~cm}$ de 5,11 e 5,22 $\mathrm{kg} \mathrm{dia}^{-1}$ de matéria seca, respectivamente, considerando consumo de $2,5 \%$ de peso médio do animal vivo. Assim, no período de pastejo de 131 dias, tem-se um consumo de 669 e $684 \mathrm{~kg} /$ animal de MS, para as intensidades de $10 \mathrm{e}$ $40 \mathrm{~cm}$. Considerando que $45 \%$ da matéria seca do tecido vegetal é $C$, vão para o subsistema animal cerca de 301 e 308 kg/animal de C, para essas intensidades de pastejo, o que representa 1.278 e $371 \mathrm{~kg} \mathrm{ha}^{-1} \mathrm{de} \mathrm{C}$, para as intensidades de 10 e $40 \mathrm{~cm}$, respectivamente. Isto pode influenciar grandemente a dinâmica da matéria orgânica no sistema solo-planta-animalatmosfera, visto que o $\mathrm{C}$ que adentra o subsistema animal pode voltar para a atmosfera via respiração, atividade de bactérias no rúmen e, ainda, a liberação de dejetos, que são mais facilmente decomponíveis. Com isso, pode-se explicar, em parte, o porquê da intensidade de $10 \mathrm{~cm}$ estar causando perdas de $\mathrm{C}$ e $\mathrm{N}$ do solo e, como consequência, de maior potencial para emissão de gases do efeito estufa.

Diversos fatores podem alterar o acúmulo de matéria orgânica no solo, principalmente quando se insere o animal. Ao se considerarem condições subtropicais, de solos sob plantio direto e com baixo teor de argila, é necessária a adição de aproximadamente 9,0 $\mathrm{Mg} \mathrm{ha}^{-1} \mathrm{ano}^{-1}$ de matéria seca para se manter o estoque inicial de $\mathrm{C}$ no solo (Vieira, 2007). Para o solo deste trabalho, por possuir alto teor de argila e óxidos, além de ter maior proteção da matéria orgânica via agregação (Souza, 2008), essa adição deve ser menor. Assim, as intensidades de 20 e $40 \mathrm{~cm}$ juntamente com a área sem pastejo têm conseguido adicionar quantidades superiores a 9,0 $\mathrm{Mg}$ ha ano ${ }^{-1}$ quando se soma a massa de raiz e da parte aérea da pastagem (Conte, 2007) de aveia e azevém juntamente com a cultura da soja, uma vez que ocorrem aumentos nos teores de $\mathrm{C}$ (Figura 1 ). 
Como citado anteriormente, aumentos nos estoques de $\mathrm{C}$ estão também relacionados a aumentos nos estoques de $\mathrm{N}$ no solo, o que significa que, quando se objetiva a recuperação dos estoques de matéria orgânica de um solo degradado, a adição de $\mathrm{N}$ ao sistema é fundamental (Vieira, 2007). Entre a utilização de fertilizantes nitrogenados minerais e a inclusão do cultivo de plantas leguminosas no sistema de rotação de culturas, o que se deduz é que o $\mathrm{N}$ adicionado via fixação simbiótica é mais eficiente que $\mathrm{o} \mathrm{N}$ adicionado via fertilizante em promover acúmulo de $\mathrm{C}$ no solo. Provavelmente é por isso que, neste estudo, em que ocorre aplicação somente de 45 a $90 \mathrm{~kg} \mathrm{ha}^{-1}$ de $\mathrm{N}$, os aumentos nos estoques de $\mathrm{N}$ no solo atingiram taxas de até $151 \mathrm{~kg} \mathrm{ha}^{-1} \mathrm{ano}^{-1}$, o que deve ser, em parte, provenientes do $\mathrm{N}_{2}$ fixado pela soja. Outro ponto, entretanto, pode estar influenciando esse alto acúmulo, é o cálculo em massa equivalente. Este método tem sido o mais utilizado para o cálculo dos estoques de nutrientes no solo, no entanto pode ter contribuído para esse alto acúmulo nesta intensidade em função da possível superestimação da massa de solo. Isso ocorre em função de a densidade utilizada para os cálculos do estoques estar baseada na maior densidade do solo que é da alta intensidade de pastejo $(10 \mathrm{~cm})$, acarretando maior massa de solo em relação à da área sem pastejo.

O Índice de Manejo de Carbono (IMC) é um indicador de qualidade do manejo do solo e permite avaliar o processo de perda ou ganho de qualidade do solo: quanto maior o IMC, maior a sua qualidade e vice-versa. Nas intensidades moderadas de pastejo, o IMC foi semelhante $(40 \mathrm{~cm})$ ou tendendo a ser superior $(20 \mathrm{~cm})$ em relação ao tratamento sem pastejo (Quadro 2), demonstrando que essas áreas têm mantido a labilidade da matéria orgânica de forma semelhante à área referência (sem pastejo), enquanto na maior intensidade de pastejo esse índice foi bastante inferior (65). Diekow et al. (2005) avaliaram um Argissolo submetido a diferentes sistemas de cultura e adubação nitrogenada sob plantio direto, utilizando como referência um campo nativo com índice 100 . No sistema com maior aporte de resíduos ao solo o IMC foi maior (256), enquanto o ICM no solo descoberto e no sistema aveia/milho sem $\mathrm{N}$ mineral foi bem mais baixo, próximo de 56 .

O IMC poderia ser utilizado com mais frequência, pois é um bom indicativo da qualidade do manejo na matéria orgânica em função dos sistemas de manejo de solo e de cultura, conforme observado neste trabalho.

\section{CONCLUSÕES}

1. Intensidades de pastejo moderadas $(20 \mathrm{e} 40 \mathrm{~cm}$ de altura do pasto) em sistemas de integração pastagem de gramíneas-soja em plantio direto promovem aumento nos estoques de $\mathrm{CO}$ total, $\mathrm{CO}$ particulado, $\mathrm{N}$ total e $\mathrm{N}$ na matéria orgânica particulada no solo, semelhantemente ao plantio direto sem pastejo.

2. $\mathrm{Na}$ alta intensidade de pastejo $(10 \mathrm{~cm})$ ocorrem perdas nos estoques desses elementos a partir do terceiro ano de condução desse sistema de integração lavoura-pecuária.

3. O índice de manejo de C (65) demonstra ter havido degradação da qualidade da matéria orgânica em alta intensidade de pastejo $(10 \mathrm{~cm})$, enquanto nas intensidades moderadas de pastejo a labilidade da matéria orgânica se equivale à área sem pastejo, com ganhos na qualidade do solo.

\section{LITERATURA CITADA}

BAGGIO, C. Comportamento em pastejo de novilhos numa pastagem de inverno submetida a diferentes alturas de manejo em sistema de integração lavoura-pecuária. Porto Alegre, Universidade Federal do Rio Grande do Sul, 2007. 87p. (Tese de Mestrado)

BAYER, C. \& MIELNICZUK, J. Características químicas do solo afetadas por métodos de preparo e sistemas de cultura. R. Bras. Ci. Solo, 21:105-112, 1997.

BIRCHAM, J.S. Herbage growth and utilization under continuous stocking management. Edinburgh, University of Edinburgh, 1981. (Tese de Doutorado)

BLAIR, G.J.; LEFROY, R.D.B. \& LISLE, L. Soil carbon fractions based on their degree of oxidation, and the development of a carbon management index, for agricultural systems. Austr. J. Agric. Res., 46:1459-1466, 1995.

BOENI, M. Proteção física da matéria orgânica em Latossolos sob sistemas com pastagens na região do Cerrado Brasileiro. Porto Alegre, Universidade Federal do Rio Grande do Sul, 2007. 136p. (Tese de Doutorado)

CAMBARDELLA, C.A. \& ELLIOT, E.T. Particulate soil organicmatter changes across a grassland cultivation sequence. Soil Sci. Soc. Am. J., 56:777-783, 1992.

CASSOL, L.C. Relação solo-planta-animal num sistema de integração lavoura-pecuária em semeadura direta com calcário na superfície. Porto Alegre, Universidade Federal do Rio Grande do Sul, 2003. 157p. (Tese de Doutorado)

COMISSÃO DE QUÍMICA E FERTILIDADE DO SOLO CQFSRS/SC. Manual de adubação e de calagem para os Estados do Rio Grande do Sul e Santa Catarina. Porto Alegre, Sociedade Brasileira de Ciência do Solo - Núcleo Regional Sul, 2004.

CONCEIÇÃO, P.C.; AMADO, T.J.C. \& MIELNICZUK, J. \& SPAGNOLLO, E. Qualidade do solo em sistemas de manejo avaliada pela dinâmica da matéria orgânica e atributos relacionados. R. Bras. Ci. Solo, 29:777-788, 2005.

CONTE, O. Atributos físicos de solo e demanda de tração em semeadura direta de soja, com diferentes pressões de pastejo em sistema de integração lavoura-pecuária. Porto Alegre, Universidade Federal do Rio Grande do Sul, 2007. 91p. (Tese de Mestrado) 
CORAZZA, E.J.; SILVA, J.E.; RESCK, D.V.S. \& GOMES, A.C. Comportamento de diferentes sistemas de manejo como fonte ou depósito de carbono em relação á vegetação de Cerrado. R. Bras. Ci. Solo, 23:425-432, 1999.

DIEKOW, J.; MIELNICZUK, J.; KNICKER, H.; BAYER, C.; DICK, D.P. \& KNABNER, I.K. Carbon and nitrogen stocks in physical fractions of a subtropical Acrisol as influenced by long-term no-till cropping systems and $\mathrm{N}$ fertilization. Plant Soil, 268:319-328, 2005.

ELLERT, B.H. \& BETTANY, J.R. Calculation of organic matter and nutrients stored in soils under contrasting management regimes. Canadian J. Soil Sci., 75:529-538, 1995.

EMPRESA BRASILEIRA DE PESQUISA AGROPECUÁRIA EMBRAPA. Centro Nacional de Pesquisa de Solos. Sistema brasileiro de classificação de solos. Rio de Janeiro, 2006. 306p.

LAL, R. Soil carbon dynamics in cropland and rangeland. Environ. Pollut., 116:353-362, 2002.

LOPES, M.L.T. Sistema de integração lavoura-pecuária: Desempenho de novilhos superprecoces e rendimento subsequente da cultura de soja. Porto Alegre, Universidade Federal do Rio Grande do Sul, 2008. 124p. (Tese de Mestrado)

LOVATO, T.; MIELNICZUK, J.; BAYER, C. \& VEZZANI, F. Carbono e nitrogênio adicionados e sua relação com o rendimento do milho e estoques destes elementos no solo em sistemas de manejo. R. Bras. Ci. Solo, 28:175-187, 2004.
SÁ, J.C.M.; CERRI, C.C.; DICK, W.A.; LAL, R.; VENZKE FILHO, S.P.; PICCOLO, M.C. \& FEIGL, B.J. Organic matter dynamics and carbon sequestration rates for a tillage chronosequence in a Brazilian Oxisol. Soil Sci. Soc. Am. J., 65:1486-1499, 2001.

SALTON, J.C.; FABRÍCIO, A.C.; MACHADO, L.A.Z. \& OLIVEIRA, H. Pastoreio de aveia e compactação do solo. R. Plantio Direto, 69:32-34, 2002.

SALTON, J.C. Matéria orgânica e agregação do solo na rotação lavoura-pastagem em ambiente tropical. Porto Alegre, Universidade Federal do Rio Grande do Sul, 2005. 158p. (Tese de Doutorado)

SOUZA, E.D.; COSTA, S.E.V.G.A.; LIMA, C.V.S.; ANGHINONI, I.; MEURER, E.J. \& CARVALHO, P.C.F. Carbono orgânico e fósforo microbiano em sistemas de integração agricultura-pecuária submetidos a diferentes intensidades de pastejo em plantio direto. R. Bras. Ci. Solo, 32:1273$1282,2008$.

SOUZA, E.D. Evolução da matéria orgânica, do fósforo e da agregação em sistema de integração agricultura-pecuária em plantio direto, submetido a intensidades de pastejo. Porto Alegre, Universidade Federal do Rio Grande do Sul, 2008. 162p. (Tese de Doutorado)

TEDESCO, M.J.; GIANELLO, C. \& BISSANI, C.A. Análises de solo, plantas e outros materiais. 2.ed. Porto Alegre, Universidade Federal do Rio Grande do Sul, 1995. 174p.

VIEIRA, F.C.B. Estoques e labilidade da matéria orgânica e acidificação de um Argissolo sob plantio direto afetado por sistemas de cultura e adubação nitrogenada. Porto Alegre, Universidade Federal do Rio Grande do Sul, 2007. 123p. (Tese de Doutorado) 